\title{
Examining the Deinstitutionalization Movement in North
}

\author{
America
}

CHAVON NILES

University of Toronto

\begin{abstract}
This paper will provide a brief history of the institutionalization movement during the nineteenth century in North America, followed by an examination of the reasons behind the deinstitutionalization movement, with the intent of understanding the repercussions of both movements. Suggestions will be presented to assist mental health professionals and the community at large in implementing programs to assists former patients integrate positively into the community.
\end{abstract}

Key words: Institutionalization, Deinstitutionalization, Eugenics, Homelessness

\section{Introduction}

The desire for a knowledgeable, progressive, "sane," and structured society determined the social value individuals who were viewed as socially deviant, poor, mad, lunatics, disabled, criminals, and the like were given in the late eighteenth century (Deutsch, 1949; Goffman, 1961; Whitaker, 2002). Due to urbanization, the push towards segregating these individuals from the normal and sane individuals in North America occurred at a slower rate compared with the rest of the world (Foucault, 1965; Simmons, 1990). By the nineteenth century, these individuals were removed from their communities and placed into 
madhouses, asylums, institutions, and, finally, into mental hospitals (Foucault, 1965; Goffman, 1961; Scull, 1977).

In order to comprehend the conditions that individuals released from mental hospitals during the latter half of the twentieth century experienced in their community, it is imperative to understand the reasons for the institutionalization movement. The information presented within this paper is from a North American perspective. Within this paper, "institutionalization" refers to the process whereby individuals deemed socially deviant, poor, mad, lunatics, disabled, criminals, and the like were placed into segregated settings (Foucault, 1965; Goffman, 1961). These segregated settings were usually located outside of cities, governed by superintendents, and supervised by poorly trained staff who were responsible for "patient care." The terms "mental illness" and "patients" are based on the societal and philosophical values of the day, which dictated that society was in need of protection from these individuals. It was believed that institutionalization would provide the type of care these individuals needed (Simmons, 1990; Whitaker, 2002). "Deinstitutionalization" is defined as the release of this socially excluded group from large-scale mental hospitals and their placement into small-scale settings within the community (Dear and Wolch, 1987; Simmons, 1990). This paper will argue that the deinstitutionalization movement was not motivated by the increased use of pharmaceuticals to treat patients in mental hospitals, nor by 
humanitarian concerns for those deemed mentally ill, but by the government's desire to cut costs (Foucault, 1965; Scull, 1977; Simmons, 1990; Whitaker, 2002).

\section{Early Treatment of Patients with Mental Illness}

\section{The Rise and Fall of Moral Treatment}

The nineteenth century saw the rise of the principles of moral treatment originally promoted by Philippe Pinel (Duetsch, 1949; Kiesler and Sibulkin, 1987) which focused on social welfare and individual rights. Before this period, society was not as concerned with the type of treatment individuals in asylums were receiving. However, Pinel stressed that society needed to move away from the religious dogma that governed treatment towards a scientific dogma which promoted the use of the medical model (Duetsch, 1949; Kiesler and Sibulkin, 1987; Reaume, 2009; Whitaker, 2002). The medical model of disability viewed impairments as residing within the individual, where medical intervention was needed for rehabilitation (Barnes, 2001; Barnes, 2003; Oliver, 1990a). Similar to Pinel, Samuel Tuke protested against the inhumane treatment individuals in asylums were receiving during the eighteenth century. Examples include being locked up in chains, placed in unsanitary conditions, ridiculed by the public and treated as less than human (Duetsch, 1949; Healy, 1997; Kiesler and Sibulkin, 1987; Reaume, 2009; Whitaker, 2002). Tuke presented society with:

a new way to think about the mad. No longer were they to be viewed as animals... [t]hey were, instead to be seen as beings within the human 
family... [where] their recovery lay inside themselves, and not in the external powers of medicine (Whitaker, 2002, p. 24-25).

Tuke encouraged asylums to use moral treatment to care for patients, which he advocated would greatly benefit their mental state (Duetsch, 1949; Whitaker, 2002). The moral treatment reform was based on the philosophy that providing patients with a family environment, daily exercise and rest, better living conditions (by monitoring what patients ate, providing clean air, and so forth), and employment opportunities would improve their health (Duetsch, 1949; Healy, 1997). Under these conditions, patients could recover and contribute back to society in the form of employment. However, the moral treatment reform was short lived due to: the increased acceptance that mental illness was a physical illness that could only be handled through medical interventions, the assertion that moral treatment was too expensive, the large influx of individuals with physical and mental illnesses. This led to overcrowding asylums and the promotion of custodial care as the treatment of choice (Healy, 1997; Kiesler and Sibulkin, 1987; Scull, 1977; Whitaker, 2002). These factors gave birth to scientific therapy which included viewing patients as having impairments that could only be treated through medical intervention. This, in turn, led to the dismantling of the ideals of moral therapy (Scull, 1977; Whitaker, 2002).

The onset of the twentieth century brought with it another change in the public's attitude based on the ideals of the eugenics principles introduced by Francis Galton a century earlier (Gould, 1981; McLaren, 1990; Whitaker, 2002). 
Eugenics was born out of the notion that social problems had a biological basis. According to this school of thought, the people with mental or physical disabilities were not victims, but rather, they were the problem (Dowbiggin, 1997; McLaren, 1990). Galton argued that preventing people deemed mentally and physically ill from marrying and procreating through, segregation, containment and sterilization would ensure that "unfit genes" would not pass on to future generations. This would in turn solve the social problems these people might potentially create (Dowbiggin, 1997; McLaren, 1990; Ridenour, 1961; Whitaker, 2002). Agnes MacPhail, Canada's first female Member of Parliament, strongly argued against the reproductive rights of Canadians with mental illness. She claimed, "I just wonder how much longer we're going to allow sub-normal people to produce their kind...would you want the worst type of your cattle to be seedbearers?" (McLaren, 1990, p.121). Other proponents of the eugenic ideal stressed that, "any society that wanted to remain strong would do well to avoid spending on its 'defectives' and would seek to keep them from breeding as well' (Whitaker, 2002, p. 46). Sterilization laws introduced during the 1930s in Canada became a means to prevent the procreation of those deemed "unfit" and believed to become an economic burden on taxpayers (McLaren, 1992). Asylums were increasingly accepted as a necessity to protect society from the mad becoming a warehouse for those deemed unfit. This had set the stage for the use of medical 
therapeutics on patients in the twentieth century (Dowbiggin, 1997; Whitaker, 2002).

Eugenics and Institutions

With the increasing population of people with mental illnesses in institutions, superintendents became dictators running institutions on minimal funds, with poorly trained and nominal amounts of staff who increasingly relied on force to keep patients under their control (Scull, 1977; Whitaker, 2002). At the same time, eugenic societies were springing up across North America with the consensus that only the "fit" should reproduce and measures should be taken to reduce the reproduction and lifespan of the unfit through immigration restrictions, sterilization, and birth control (Dowbiggin, 1997; McLaren, 1990). The eugenics movement opened the gate for the use of invasive medical therapies in asylums (Whitaker, 2002). Once again, various forms of invasive procedures were used on people with mental illness with the goal of restraining them (Dowbiggin, 1997;

Whitaker, 2002). Some of the most well-known forms of invasive treatments used during this period include: insulin coma therapy, electroshock therapy, and prefrontal lobotomy (Dowbiggin, 1997; Healy, 1997; Reaume, 2009; Ridenour, 1961; Scull, 1977; Simmons, 1990; Whitaker, 2002). These therapies altered patients' behaviours making them more manageable for attendants (Dowbiggin, 1997; Ridenour, 1961; Scull, 1977; Whitaker, 2002). The use of lobotomies also enabled the field of psychiatry to transform itself into an academic medical field, 
signaling its arrival as a scientific discipline (Simmons, 1990; Whitaker, 2002).

The use of invasive medical procedures reflected the underlying societal values of the eugenic attitude during the first half of the twentieth century (Dowbiggin, 1997; Scull, 1977; Whitaker, 2002).

\section{The Move to Deinstitutionalize}

Within North America, during the late 1930s, administrators in mental hospitals were increasingly struggling with inadequate budgets and overcrowded facilities (Scull, 1977; Simmons, 1990; Whitaker, 2002). In addition, the aftermath of World War II brought with it greater awareness of the poor treatment of people with mental illnesses in mental hospitals (Rose, 1979; Scull, 1977). During this time, in Nazi Germany, there was a push to purify the German people through compulsory sterilization of those believed to be born with mental and physical illnesses. As the ramifications of the eugenics polices applied in Nazi Germany came to light, North American society came to question the types of treatments used to control rather than care for those deemed mad (McLaren, 1990; Scull, 1977). This led to the consideration of more humane forms of treatment in the community setting. The information presented below aims to shed light on the reasons that have been suggested for the deinstitutionalization movement in North America with the goal of understanding who this movement benefited. 
HEALTH TOMORROW, VOL. 1(2013).

\section{Drugs and Corruption}

An increased use of neuroleptics (particularly the early use of

Chlorpromazine), coupled with the mounting belief that it was possible to care for patients in the community, has been viewed as one of the reasons behind the deinstitutionalization movement (LaJeunesse, 2002; Ridenour, 1961; Simmons, 1990; Turner, 2004; Whitaker, 2002). Chlorpromazine, commercially known as Thorazine and Largactil, was originally used to treat various disorders from allergies to malaria. In the latter half of the twentieth century, Chlorpromazine was used for pain relief where it produced "tranquilizing effects" by altering a patient's mood, thinking, and behaviours (LaJeunesse, 2002). Soon Chlorpromazine was hailed as the drug that would provide "humane outcomes" for patients and its use spread rapidly throughout American asylums (Healy, 1997; LaJeunesse, 2002; Scull, 1977). Reports were published in the United States showcasing how the use of neuroleptics led to the decline in the number of patients in mental hospitals by stabilizing their behaviours (LaJeunesse, 2002; Mechanic and Rochefort, 1990; Scull, 1977; Whitaker, 2002). Governments advocated for outpatient treatments and for resources to be allocated in the community, thus replacing the need for mental hospitals (Whitaker, 2002). Psychiatry also prided itself on being able to offer patients "curative pills" that were easy to administer instead of the other invasive and controversial procedures 
used prominently earlier (LaJeunesse, 2002; Mechanic and Rochefort, 1990; Scull, 1977).

Although the public and the government's voices were heard in regards to the administration and implementation of neuroleptics, the voices of patients forced to take these drugs and participate in experimental studies were seldom, if ever, heard. The quote below explains how some staff members felt about drugs being administered to patients without their consent.

Some staff members expressed concern about drug studies which were done without patients' consent-and often without their knowledge. Patients drooled, others walked "sloping forward," some trembled, and others became rigid. And for many, the drugs did very little good. Tim Yu ...was a tiny "compulsive" man. He couldn't seem to control his behaviour and walked in circles all day. The new tranquilizers reduced the circumference of his circle (LaJeunesse, 2002, p.128).

Whitaker (2002) further discusses how patients responded to neuroleptics

by stating that, "[s]ome patients experienced the drug-induced change... as a

positive [change.]... [They] report[ed] that the drug made them feel calmer, less

fearful, and even clearer in mind" (p. 175). Whitaker (2002) also explains that few studies published results that discussed patients' negative drug experiences. Of the few that were published, Janet Gotkin, a former patient, explains that she became, "a stranger in the normal world, a prisoner of drugs and psychiatric mystification, unable to survive anywhere but in the psychiatric hospital..." (Whitaker, 2002, p. 176). Janet Gotkin's personal experiences allows us to further understand the long term mental and physical affect of drugs used to "cure" her 
illness. The negative side effects of neuroleptics suggest that the early findings that praised it as a medical breakthrough may have exaggerated the therapeutic gains (LaJeunesse, 2002; Scull, 1977; Whitaker, 2002). While the use of the drug did lead to patients becoming quieter, and to an increase in their docile state, patients were already being released prior to the implementation of drug treatments in mental hospitals (Scull, 1977). Therefore, it can be argued that the use of neuroleptics did not significantly affect release rates. Moreover, once patients were released from mental hospitals, many chose not to continue taking the drugs on a regular basis. This led to the "revolving-door syndrome" in which patients were admitted, treated with medication, discharged, abandoned, and then readmitted (LaJeunesse, 2002).

The political and monetary gains made by the government and drug manufacturers with the increase use of neuroleptics in mental hospitals raise the question as to who truly benefited from their usage (Scull, 1977; Whitaker, 2002). This is because neuroleptics transformed the mental health care sector into being under the influence of the pharmaceutical industry (Scull, 1977; Whitaker, 2002). In the United States prior to 1951 , for example, drug manufacturers needed to receive a seal of approval from the American Medical Association (AMA) for their drugs to be used by patients (Whitaker, 2002). This could be accomplished quite easily since drug manufactures only had to prove that their drug was not toxic. Moreover, the AMA was solely responsible for distinguishing between 
good and bad drugs since there were no government regulations in place prior to 1951 requiring pharmaceutical companies to prove the effectiveness of their drug (Whitaker, 2002, p. 148). In addition, patients did not need to obtain physicians approval and manufacturers could charge as much as they wanted in the overseas market. Therefore, the AMA was able to profit from the increased distribution of pharmaceutical drugs in and out of mental hospitals (Whitaker, 2002). It was not just,

... the AMA that was corrupted [and was profiting from the distribution of neuroleptics in mental hospitals and in the community.]...[M]arketing machinery of pharmaceutical firms completely altered what physicians, and the general public read about new medications [.]... [M]edical journals...exaggerated the benefits of new drugs and obscured their risk...(Whitaker, 2002, p. 149).

This suggest that the claim made by some mental hospitals and pharmaceutical companies that neuroleptics played a large role in the deinstitutionalization of patients from mental hospitals is questionable. This is because the information presented to the general public concerning the use of neuroleptics was molded by the pharmaceutical industry's marketing teams (LaJeunesse, 2002; Scull, 1977; Whitaker, 2002). A study by Gronfein (1985) examined the specific role of psychotropic drugs before and after deinstitutionalization. Results from this study indicated that psychotropic drugs alone were not significantly responsible for the movement of patients into the community. Rather, these drugs encouraged policy changes that sped up 
deinstitutionalization in the latter half of the twentieth century. Gronfein's (1985) findings support Whitaker (2002) and Scull (1977) who both assert that the use of neuroleptics was not solely responsible for the deinstitutionalization movement.

Scull (1977) explains how Brill and Patton attributed the change in hospital population to the administration and prescription of neuroleptics. While there was a relationship between drug prescription and release rate, the authors failed to clearly identify the drug's influence as an isolated factor and the specific role of psychopharmacology. Furthermore, Brill and Patton's study did not provide a control group of individuals who had not received drug treatment. Within the Brill and Patton study, external changes in regards to social, legal, economic, administrative, and technical forces were cited as encouraging the movement of patients from mental hospitals into the community.

These findings suggest pharmaceutical companies had much to gain financially by pushing the use of drugs in mental hospitals, which coincided with the reformation of public policies, public opinions about mental illness, and placement options available in the community (LaJeunesse, 2002; Lewis et al., 1991; Scull, 1977; Whitaker, 2002).

\section{Attitudes and the Move to Community Care}

In the latter half of the twentieth century, the mental health care system was going through an organizational transformation from custodial care to publicly funded community care (Mechanic and Rochefort, 1990; Rose, 1979; 
Scull, 1977). Therefore, patients were to be moved from mental hospitals and be treated in a community setting. Moreover, society’s attitudes towards mental illness began to shift away from the medical model of disability, giving rise to the anti-psychiatry movement in the sixties and seventies (Ridenour, 1961; Turner, 2004), in which deinstitutionalization was accepted as a more appropriate and humane option (Lamb and Bachrach, 2001; Rose, 1979).

This new concept was grounded within the social model of disability, which stressed that it was not the individual who was in need of change; rather, it was the environmental, physical, and societal barriers that needed to be changed to include patients in the community (Oliver, 1990a; Oliver, 1990b; Scull, 1977; Whitaker, 2002). Moreover, society became increasingly aware of the isolation and the control mental hospitals had over patients' lives (Lewis et al., 1991). Another reason that has been suggested for the deinstitutionalization movement has been society's realization of the ill treatment patients were receiving in mental hospitals. If deinstitutionalization was indeed due to humanitarian efforts, then large scale community resources would have been implemented before patients were released (Simmons, 1990; Scull, 1977). Returning patients to the community did not indicate that society's tolerance resulted in the mass release of patients from mental hospitals (Scull, 1977; Whitaker, 2002). 
Although the public became more cognizant of patients' actual living conditions in mental hospitals, there was still a large public protest as to where newly released patients should reside (Reaume, 2009; Scull, 1977; Talbott, 1979). This was largely due to the stigma attached to mental illness. Scull (1977) explains how communities' attitudes towards the placement of ex-patients into upper middle class neighbourhoods elicited negative reactions where efforts were made to remove or stop these individuals from moving into the communities. This was successfully accomplished by middle and upper class communities. Without family support many ex-patients ended up in segregated community settings with other patients (Dear and Wolch, 1987; Scull, 1977; Talbott, 1979) further suggesting that the deinstitutionalization movement was not motivated by humanitarian concerns.

\section{Economic Costs and a Changing Society}

Different reasons have been suggested to explain why the deinstitutionalization movement in North America picked up momentum in the latter half of the twentieth century. Some researchers suggest that the increasing cost of maintaining mental hospitals, combined with the advancement of society into a capitalist, urbanized place where larger sums of money were needed for urban development to continue (Lamb and Bachrach, 2001; Scull, 1977) made deinstitutionalization more appealing (Rose, 1979; Simmons, 1990; Talbott, 1979; Whitaker, 2002). The widespread unionization of employees, the eight-hour days 
and forty-hour work week, coupled with the rise in the number of class action suits against mental hospitals during the sixties and seventies on behalf of patients reporting mistreatment, and the need for minimum standards of treatment in mental hospitals may have also assisted in the push to discharge patients at a quicker rate (Scull, 1977; Whitaker, 2002).

From an economic standpoint, deinstitutionalization was not aimed at improving the situation of ex-patients since there were no detailed community services put into place to assist this group with integration. A former medical superintendent of the Queen Street Mental Health Centre, in Ontario Canada, during the early 1970s, explains the messages he was receiving with regards to the maintenance fees of mental hospitals. He states,

Pretty explicit messages were associated with budget cuts, close units, lock the door, and don't use them. That meant you could use the staff that was operating a unit and consolidate...I can remember reading pretty specific directives that this was what the government wanted to see happen (Simmons, 1990, p.160).

This suggests that the initial decline in the number of patients in Ontario's mental hospitals was a deliberate move to discharge patients into the community irrespective of the quality and functionality of the community support services available, rather than a carefully planned and executed policy that outlined a network of community support services. By deinstitutionalizing patients, the government was able to save a substantial amount of money and present society with the belief that this was being done under the guise of humanitarian care for 
the once rejected. Deinstitutionalization also allowed for the redistribution of money that would have been spent on expanding mental hospitals, hiring and training staff, maintaining these facilities towards research, urbanization, and enhancing and expanding the public education system (Scull, 1977; Simmons, 1990).

Additionally, the economical means of caring for patients shifted the tax burden in the United States, from the state to federal taxpayers (Krieg, 2001; Talbott, 1979). These individuals were now to be supported in the community by the federal government that was to provide social security for ex-patients (Scull, 1977; Whitaker, 2002). Welfare regulations were also changed to assist expatients discharged into the community (Scull, 1977). Moreover, screening processes were implemented to encourage community placements in non-hospital settings, especially for geriatric cases, and involuntary commitment was made far more difficult; further aiding in the reduction of hospital intake (Whitaker, 2002).

It appears that the driving force behind the deinstitutionalization movement was largely influenced by the government's desire to save money by eliminating the fixed costs of mental hospitals. This decision would lead to a state of uncertainty and many problems for ex-patients discharged into the community.

\section{Repercussions of the Deinstitutionalization Movement}

Releasing patients into the community had the potential to bring forth more humane and therapeutic alternative community services compared to 
hospital care (Dear and Wolch, 1987; Lamb and Bachrach, 2001). In addition, former patients were to be placed in environments where they would be able to rebuild their lives and have access to a social network that would assist them in integrating successfully into the community (Williams, 1976). External support networks affected discharged patients' prospects for survival in the community (Reaume, 2009), since family and friends had a much larger role to play in assisting them with their new living arrangements (Grimes and Vitello, 1990; Scull, 1977; William, 1976). Without the support of family and friends, expatients risked being isolated and alone in a community they were once shunned from. Even if social networks were present, there was no guarantee that patients would receive quality care in the community. Williams (1976) investigated familial attitudes towards having a discharged family member living in the family home. Many reported an increase emotional burden and social costs associated with taking care of the ex-patient. In addition, the greater the individual's needs the less tolerant; more burdened, trapped, and isolated families reported feeling. Due to the increasing closure of mental hospitals and the complex readmission criteria, some family members reported that they had nowhere or no one to turn to. This led to strained relationships and neglectful treatment for those most in need of supportive care.

For ex-patients who were poor, or those with little or no social contact outside of mental hospitals, deinstitutionalization posed a greater challenge. 
Reaume (2009) in Remembrance of Patients Past explains the story of two male patients who requested not to be discharged until they could secure employment, since they had nowhere to go. These two cases illustrate that for some patients, in the pre-welfare state, mental institutions served as a shelter. In some instances, community support or social networks were not available. These individuals relied on mental hospitals to serve, support, and shelter them. Without such support, patients' placement into the community tended to be unsuccessful since there was a lack of services to assist them with achieving at least a minimal standard of living (Scull, 1977). This led many to live on the streets, to be reinstitutionalized, or incarcerated in jail or prison (Dear and Wolch, 1987; Lamb, 2001).

\section{Deinstitutionalization and Community Care}

It was widely accepted that deinstitutionalization would allow patients to have access to healthier living conditions compared to the vile and inhumane conditions of mental hospitals (Dear and Wolch, 1987; Scull, 1977). However, laws with reference to community care and community living did not detail how people with disabilities would be received and treated once in the community (Simmons, 1990). A psychiatrist working in Canada during the deinstitutionalization movement gives the following explanation of how it was viewed: 
Deinstitutionalization was an incredible thing...all you had to do was to load them with neuroleptic drugs and send them into the community. We began reading Erving Goffman and Ernest Gruenberg from New York State and how hospitals screw people up. So we took tens of thousands of patients and threw them out of the hospital without any support system. We said there was going to be follow-up, but the fact of the matter is that nobody really understood, so the bureaucrats were delighted to get them out of hospitals....and only...later did we say, "Hey, this is crazy, what about housing, what about recreation?" (Simmons, 1990, p.160).

Despite the public health care system and a welfare system in Canada, expatients moving into the community experienced similar conditions as their American counterparts due to underfunding and lack of quality community support services. Harvey Simmons (1990) in Unbalanced explains that in 19861987, the ten provincial psychiatric hospitals in Canada consumed $35.2 \%$ of mental health expenditures while a mere $4.9 \%$ was devoted to community mental health. Specifically, in Ontario, the unbalanced community mental health services was the direct result of a system that was underfunded, understaffed in psychiatric hospitals and had an inadequate, unprepared, and under-serviced community care program. Moreover, there was no organized aftercare program for patients discharged from provincial mental hospitals until the 1930s. While clinics may have wanted to do more, they were continually on the move, swamped with work, and felt that their role was to inform local physicians about the presence of a discharged patient in the community. While most provincial mental hospitals had implemented an aftercare program by 1945, these programs still lacked the personnel and the resources to do an effective job, leaving many with a vague 
idea of what aftercare meant. By the early 1960s, there was still no policy on aftercare program for ex-patients in the Department of Health in Ontario (Simmons, 1990).

\section{The Search for a Home}

Research concerning housing arrangements and location for ex-patients revealed that once released from mental hospitals these individuals were either living; alone, with family/relatives, in supervised conditions in nursing homes (Scull, 1977), board and care facilities, sheltered housing, halfway houses or living on the streets (Kiesler and Sibulkin, 1987). Within the community, expatients were still segregated from the general public. This raises the question as to whether institutionalization was given a new name under the guise of supportive housing. Within supportive housing, ex-patients were housed away from mainstream society in the community (Scull, 1977). Moreover, ex-patients tended to gravitate towards old, rundown neighbourhoods which were once:

...the zone of transition...an area of property speculation, housing conversion and cheap accommodation and services, had become more than ever the home for society's marginal people... (Dear and Wolch, 1987, p. 13).

This was because ex-patients were excluded from suburban, residential neighbourhoods where increasing funds were being redistributed (Dear and Wolch, 1987; Scull, 1977). While this was occurring, in the United States, the welfare state was in the process of privatizing welfare provisions where, "...direct state services... [were]...being replaced by commercial and non-profit service 
sector, and the general level of service provision... [was]...being curtailed..." (Dear and Wolch, 1987, p. 198). The economy was in a greater state of transition as welfare provisions, once guaranteed to each ex-patient, were restructured. This meant that ex-patients receiving minimum services in the community experienced greater negative changes in the nature and quality of the services they were now provided with. For many, this exacerbated their conditions in an already impoverished and highly stressed environment (Dear and Wolch, 1987). The cutbacks in social services and the absence of fully developed, coordinated, and funded community-based programs failed to provide the necessities ex-patients needed to find a place of their own to live and thrive in the community (Dear and Wolch, 1987; Scull, 1977; Simmons, 1990).

\section{The Prominence of Homelessness among Ex-Patients}

A large number of ex-patients ended up residing on the city streets or congregating in low-cost housing in deteriorating neighbourhoods (Talbott, 1979). Researchers have argued that the reason why the presence of individuals with mental illness has increased steadily among the homeless population is due to the failure of program developers to provide adequate alternative forms of treatment programs, services, and resources to support ex-patients in the community after deinstitutionalization (Kiesler and Sibulkin, 1987; Lamb and Bachrach, 2001; Mechanic and Rochefort, 1990). Mechanic and Rochefort (1990) conducted a comprehensive overview to investigate the causes and consequences of 
deinstitutionalization in the United States. Their study revealed that ex-patients did not receive greater access or improved quality of services after deinstitutionalization, leaving many of them without essential services and leading to homelessness. Additionally, once patients were released from mental hospitals they may have stopped taking their medication. Without any supervision from hospitals or community social support these individuals became lost in the system. Kiesler and Sibulkin (1987) also addressed the unsolved problems arising from homelessness by suggesting that simply committing additional resources to assist ex-patients in and out of the hospital does not guarantee an increase in the quality of care. Therefore, service providers should have changed their policies to assist ex-patients in and out of mental hospitals to increase their quality of life.

While shelters were provided in communities to house people who were homeless for a short period of time, these shelters socially isolated ex-patients from the rest of the community, increasing the gap between the sane and housed and the insane and homeless (Dear and Wolch, 1987). In many cases, primary support services were unavailable and inadequate. This increased the probability that ex-patients who had difficulties living in less protected environments and who lacked support networks in the community would end up homeless (Dear and Wolch, 1987; Scull, 1977). Although funding was provided in the community, it was provided at levels far below that needed to successfully support these 
individuals' needs (Dear and Wolch, 1987; Simmons, 1990). Cutbacks in social services and the absence of fully developed, coordinated, and funded communitybased programs for ex-patients further exacerbated their problems in the community. Moreover, the underutilization of existing resources by ex-patients who were not educated on how to obtain social services in the community coexisted with other debilitating factors in the community. This provided some individuals with no other choice but to find a place on the street to spend the remainder of their days.

\section{Coming Full Circle: Reinstitutionalization/ Incarceration}

While some ex-patients ended up living on the streets, others ended up being incarcerated in mental hospitals or in jails (Dear and Wolch, 1987). Dr. J. S. Pratten, one of the medical superintendents of Kingston, Ontario in the latter half of the twentieth century, noted that the discharge rate in provincial hospitals was about $75 \%$ for new admissions while the readmission rate was between $35 \%$ to $50 \%$ within a few months of patients leaving the hospital. Dr. Pratten suggested that closer contacts with public health units and other community agencies may assist patients, since the current services offered did not provide adequate aftercare for patients in need (Simmons, 1990). Similar readmission trends was occurring in the United States which led Ozarin and Sharfstein (1978) to examine why there was an increased number of ex-patients reinstitutionalized. These authors found that the limited access to quality care, substandard living 
conditions, and inadequate support services in the community resulted in expatients' readmission to mental hospitals. Moreover, while patients may have communicated their needs to professionals, the resources allocated to meet their needs were limited or not present at all in the community. This was because patients released from mental hospitals did not drastically cause an increase in community care facilities being constructed. For patients with no ties to the community, initially poor, or with substantial needs, the chances of successfully transitioning into the community, and them seeking or receiving community services was reduced, leading to their subsequent reinstitutionalization or incarceration (Dear and Wolch, 1987; Simmons, 1990; Turner, 2004).

Given that the number of ex-patients incarcerated rose suggests that these individuals did not benefit significantly from the deinstitutionalization movement. Dear and Wolch (1987) argue that this was due to, "[t]he lack of adequate community supports...[which]...led to...[their]...incarceration....within the criminal justice system for crimes more indicative of their mental health disabilities than criminal intent" (p. 174). Ex-patients may have been incarcerated due to the insufficient amount and quality of community based residential and psychiatric facilities available. In addition, the pressure to decrease the amount of patients admitted to mental hospitals and society's intolerance of individuals with mental illnesses may have also contributed to their increased presence in jails and hospitals. Since ex-patients failed to receive the support needed to survive and 
prosper in the community, hospitals and jails increasingly became the home for the deinstitutionalized homeless (Dear and Wolch, 1987).

\section{Suggestions for Improvements}

Lamb and Bachrach (2001) suggest that for deinstitutionalization to be successful services must be culturally customized to meet the needs of each patient rather than simply changing the locus of care. This involves patients being active participants in designing their service plan with greater access to hospital care. Past ideologies should also not restrict service systems and ex-patients should receive continuous care throughout their lives, if needed. If society provides adequate care, treatment, and when necessary, hospitalization, this may aid in providing richer experiences regardless of an individual's mental state (Lamb and Bachrach, 2001; Minkoff, 1987).

Through an examination of the psychiatric services offered to ex-patients in the community, Geller (2000) adds that staffs in the mental health field are too focused on the locus of care and treatment rather than on the humaneness, effectiveness, and quality of care patients receive. Therefore, service providers should be trained to provide greater quality services in a more holistic fashion that reflects the individual's personal needs. This would assist in ensuring individuals are receiving the help needed to be successful in the community. Hope (2005) explains that for ex-patients, support included financial resources, interpersonal relationships, and supportive environments which promoted autonomy. The 
mainstream professional approach contrasted sharply with ex-patients by prioritizing support through various forms of medical treatment (e.g. medication) to manage ex-patients' behaviour. Service providers also stressed the importance of collaborative decision-making involving a team of professionals that excluded ex-patients to reduce hospitalization and increase functioning in the community. The mainstream professional treatment model reflects how treatments were traditionally implemented from the medical model of disability where patients were isolated and excluded from the decision making process, thus limiting their opportunities to truly benefit from the services. These studies exemplify the importance of educating service providers on how to develop appropriate and successful services with ex-patients to increase their quality of life. They also reveal the contrasting views of consumers and providers with regards to services, suggesting that there is a lack of communication occurring between these two groups which need to be addressed and dealt with accordingly for ex-patients to truly benefit from community integration.

Lastly, programs in the community should aid in providing greater social contact and support as many patients do not have a support circle of friends in the community, nor the skills to obtain a good job, or their family's support (Reaume, 2000; Scull, 1977). Without proper support within the community, these individuals are increasingly likely to regress and end up homeless, reinstitutionalized, or incarcerated (Dear and Wolch, 1987). 
This paper aimed to provide an overview of how society's perception of individuals with mental illness shaped the social value and the type of treatment they received from the onset of institutionalization to their deinstitutionalization from mental hospitals in North America. Understanding that institutionalization was initially based on the ideals of the medical model of disability can assist us in working to deconstruct the foundation this model was built on in order to promote a more holistic approach to caring for ex-patients in society. Furthermore, changing the locus of care, increasing the amount and quality of social services, and providing supportive alternatives in the community may assist in preventing ex-patients from being homeless, reinstitutionalized, or incarcerated in jail.

\section{References}

Barnes, C. (2001). 'Emancipatory' Disability Research: project or process? Proceedings from Public Lecture at Public Centre for Disability Studies Department of Sociology and Social Policy. City Chambers, Glasgow: University of Leeds.

Barnes, C. (2003). What a difference a decade makes: reflections on doing 'emancipatory' disability research. Disability \& Society, 18(1), 3-17.

Dear, M., \& Wolch, J. (1987). Landscapes of Despair: From reinstitutionalization to Homelessness. Princeton, NJ: Princeton University Press.

Dowbiggin, I. R. (1997). Keeping America Sane: Psychiatry and Eugenics in the United States and Canada, 1880-1940. Ithaca, NY: Cornell University Press. 
Finkel, A. (2006). Social Policy and Practice In Canada: A History. Waterloo: Wilfrid Laurier University Press.

Foucault, M. (1965). Madness and civilization; a history of insanity in the age of reason. New York: Pantheon Books.

Geller, J. L. (2000). The Last Half-Century of Psychiatric Services as Reflected in Psychiatric Services. Psychiatry Service, 51, 41-67.

Goffman, E. (1961). Asylums: Essays on the Social Situation of Mental Patients and Other Inmates. New York: Doubleday.

Gould, S. J. (1981). The Mismeasure of Man. New York: Norton and Company.

Grimes, S. K., \& Vitello, S. J. (1990). Follow-Up Study of Family Attitudes Toward Deinstitutionalization: Three to Seven Years Later. Mental Retardation, 28(4), 219-25.

Gronfein, W. (1985). Psychotropic Drugs and the Origins of Deinstitutionalization. Social Problems, 32(5), 437-454.

Healy, D. (1997). The Antidepressant Era. Cambridge: Harvard University Press.

Hope, M. (2005). Exploring the Meaning of "Support" in Supported Housing for Individuals Diagnosed Mentally Ill: A Literature Review. Variegations, 2, 34-45.

Kiesler, C. A. \& Sibulkin, A. E. (1987). Mental Hospitalization: Myths and Facts about a National Crisis. Newbury Park, CA: Sage Publications.

Krieg, R.G. (2001). An Interdisciplinary Look at the Deinstitutionalization of the Mentally Ill. The Social Science Journal, 38, 367-380.

LaJeunesse, R. A. (2002). Political Asylums. Edmonton: Muttart Foundation.

Lamb, R. H. (2001). Best of New Directions for Mental Health Services, 19792001. San Francisco, CA: Jossey-Bass.

Lamb, R. H. \& Bachrach, L.L. (2001). Some Perspectives on Deinstitutionalization. Psychiatric Services, 52(8), 1039-1045. 
Lewis, D. A., Riger, S., Rosenberg, H., Wagenaar, H., Lurigio, A. J., Reed, S., (1991). Worlds of the Mentally Ill: How Deinstitutionalization Works in the City. Carbondale: Southern Illinois University Press.

McLaren, A. (1990). Our Own Master Race: Eugenics in Canada, 1885-1945. Toronto: McClelland \& Steward.

Mechanic, D. \& Rochefort, D. A. (1990). Deinstitutionalization: An Appraisal of Reform. Annual Review of Sociology, 16, 301-327.

Minkoff, K. (1987). Beyond Deinstitutionalization: A New Ideology for the Postinstitutional Era. Hospital Community Psychiatry, 38, 945-950.

Oliver, M., (1990a). The Individual and Social Models of Disability. Basingstoke: McMillan. 1-7.

Oliver, M. (1990b). The Politics of Disablement, Chapter 8. Basingstoke: McMillan.

Ozarin, L.D. \& Sharfstein, S. S. (1978) The Aftermaths of Deinstitutionalization: Problems and Solutions. Psychiatric Quarterly, 50(2), 128-132.

Reaume, G. (2000). Remembrance of Patients Past: Patient Life at the Toronto Hospital for the Insane, 1870-1940. Don Mills, ON: Oxford University Press.

Ridenour, N. (1961). Mental Health in the United States: A Fifty Year History. Cambridge, Massachusetts: Harvard University Press.

Rose, S. M. (1979). Deciphering Deinstitutionalization: Complexities in Policy and Program Analysis. Health and Society, 57(4), 429-460.

Scull, A. (1977). Decarceration. Cambridge: Polity Press.

Simmons, H. G. (1990). Unbalanced: Mental Health Policy in Ontario, 19301989. Toronto: Wall and Thompson.

Stancliffe, R. J., Lakin, K. C., Shea, J. R., Prouty, R. W., \& Coucouvanis, K. (2004). 1-6. The Economics of Deinstitutionalization. In R. J. Stancliffe \& K. C. Lakin (Eds.), Cost and Outcomes of Community Services for People With Intellectual Disabilities. Baltimore: Paul H. Brookes Publishing Co. 
Talbott, J. A., (1979). Deinstitutionalization: Avoiding the Disasters of the Past. Hospital and Community Psychiatry. 30(9), 621-624.

Turner, T. (2004). The History of Deinstitutionalization and Reinstitutionlization. Psychiatry, 3(9), 1-4.

Whitaker, R. H. (2002). Mad in America: Bad Science, Bad Medicine, and the Enduring Mistreatment of the Mentally Ill. Cambridge, MA: Perseus Press.

William, D. (1976). Family Coping With the Mentally Ill: An Unanticipated Problem of Deinstitutionalization. Hospital Community Psychiatry, 27,183-185. 